\title{
Intima-media thickness evolution after treatment with infliximab in patients with rheumatoid arthritis
}

This article was published in the following Dove Press journal:

International Journal of General Medicine

29 July 2009

Number of times this article has been viewed

\author{
Pierpaolo Di Micco ${ }^{1,2}$ \\ Paola Ferrazzi' \\ Luca Librè' \\ Loredana Mendolicchio' \\ Ilaria Quaglia' \\ Monica De Marco' \\ Anna Colombo' \\ Monica Bacci' \\ Lidia Luciana Rota' \\ Corrado Lodigiani'
}

IThrombosis Center, Istituto Clinico Humanitas, Rozzano (MI), Italy;

${ }^{2}$ Internal Medicine, Fatebenefratelli

Hospital of Naples, Italy
Correspondence: Pierpaolo Di Micco Internal Medicine, Fatebenefratelli Hospital of Naples, via san giacomo dei capri 69-80I3I - Naples, Italy Email pdimicco@libero.it
Background: Atherosclerosis is a well known progressive disease that recognizes risk factors such as diabetes, hypertension, smoking, dyslipidemia, and inflammation. Mechanisms underlying atherosclerotic processes during inflammation are not completely understood, but cytokines are also involved, in particular tumor necrosis factor- $\alpha$ (TNF- $\alpha$ ). Chronic inflammatory diseases such as rheumatoid arthritis (RA) are commonly associated with atherosclerotic complication. Little is known about the role of treatment of chronic inflammatory disease on the evolution of atherosclerosis in this kind of disease. Usually, evolution of atherosclerosis is monitored by intimamedia thickness and the presence of plaques on several arteries such as common carotid.

Aim: The aim of the study was to monitor atherosclerosis evolution in seven RA patients on common treatment with infliximab (an anti-TNF- $\alpha$ drug) compared with seven RA patients during common treatment but not treated with infliximab.

Patients and methods: We selected 14 patients with RA according to the American College of Rheumatology classification criteria. Seven patients were selected before and after common treatment for RA based on nonsteroidal anti-inflammatory drugs (NSAIDs), methotrexate, and steroids (12 months), and seven patients before and after treatment based on infliximab associated with NSAIDs, methotrexate, and steroids (12 months). Ultrasound vascular imaging was performed to screen intima-media thickness and the presence of atherosclerotic plaques on common carotid artery and identify evolution of atherosclerosis.

Results: After 12 months, patients that were treated with infliximab showed significant worsening of atherosclerosis with an increase of intima-media thickness and the presence of further atherosclerotic plaques compared to patients that were treated traditionally and showed a nonsignificant increase of the same parameters.

Discussion: Treatment based on anti-TNF- $\alpha$ such as infliximab shows a worsening evolution of atherosclerosis based on our data. If these data are associated with a poor clinical outcome such as atherothrombosis of cerebral vessels and/or coronary vessels, this should be evaluated by further studies.

Keywords: atherosclerosis, infliximab, rheumatoid arthritis, intima-media thickness

\section{Background}

Atherosclerosis is a well known progressive disease with risk factors that were recognized by the Framingham study (ie, aging, hypercholesterolemia, hypertension, diabetes, smoking, and family history of atherothrombosis). ${ }^{1}$ Recently inflammation has been recognized as an additional atherosclerotic risk factor. ${ }^{2}$ Mechanisms underlying atherosclerotic processes during inflammation are not completely understood, but increased production of reactive oxygen species (ROS) seems to be involved and 
seems to negatively interfere with reverse cholesterol transport and triggering atherosclerotic processes. ${ }^{3-5}$

Chronic inflammatory diseases such as rheumatoid arthritis (RA) are frequently associated with accelerated atherosclerosis $^{6}$ and with severe clinical presentations. ${ }^{7}$ Moreover, several markers of inflammation such as C-reactive protein (CRP) are frequently increased in patients with atherosclerosis. On the other hand, any cytokine is increased during inflammation and are involved in atherosclerotic processes. Some authors report increased levels of several cytokines during RA such as intercellular adhesion molecule-1 (ICAM-1), interleukin-6 (IL-6), and tumor necrosis factor- $\alpha$ (TNF- $\alpha){ }^{8}{ }^{8-10}$

It is still unknown whether treatment of inflammatory disease may improve the prognosis of atherosclerotic complication in patients with RA. In particular, data about the evolution of atherosclerosis in patients with RA taking ongoing anti-TNF- $\alpha$ drugs such as infliximab are lacking.

This article evaluates the atherosclerotic evolution of patients with RA on ongoing treatment with infliximab compared to patients on ongoing common treatment by the evaluation of intima-media thickness (IMT) and/or the presence of atherothrombotic plaques on common carotid with ultrasound imaging.

\section{Patients and methods}

\section{Patients}

We selected 14 consecutive patients affected by RA according to the American College of Rheumatology classification criteria. Patients were randomly divided into two different groups and assigned to two different treatment programs: group A included patients selected for therapy based on treatment with nonsteroidal anti-inflammatory drugs (NSAIDs) on demand, steroids (per os, daily), methotrexate (intramuscular, weekly), and inflixmab ( $3 \mathrm{mg} \backslash \mathrm{kg}$ at time 0 and every eight weeks for one year); group B acted as a control group and included patients selected for common treatment based on NSAIDs on demand, steroids (per os, daily), and methotrexate (intramuscular, weekly).

Group A included seven patients (six females and one male; median age, 56 years), while group B included seven patients (six females and one male; median age, 53 years).

\section{Atherosclerosis evolution}

Identification of atherosclerosis was performed with ultrasound imaging with a 7-10 Mhz linear probe (Vivid 4; GE Milan, Milan, Italy) in order to detect atherosclerotic plaques and the presence and the evolution of IMT.
Ultrasound imaging was performed at the beginning of treatment (time 0 ) and after 12 months (time 1) of treatment for both groups.

Detection of IMT was performed three times on common carotid of both sides at the origin and at the bulb for all patients according to guidelines suggested by the Italian Society for Angiology and Vascular Medicine. The median value of three detections was considered as the main value.

The imaging evaluation was performed as a double-blind evaluation by two different physicians.

\section{Clinical score}

Disability related to RA for all patients was monitored according to the Health Assessment Questionnaire (HAQ) disability index ${ }^{11,12}$ and Disease Activity Score using 28 joint counts (DAS 28) $)^{11,12}$ at the beginning and at the end of treatment (ie, time 0 and time 1).

\section{Laboratory prognostic markers}

Values of CRP were analyzed at time 0 and time 1 in order to have a laboratory follow-up screening of the evolution of RA in all selected patients in both groups.

\section{Statistical analysis}

Statistical analysis was performed with Student's $t$-test for paired data. Data were considered to be significant if $p$ value was $<0.05$.

\section{Results}

Our results are summarized in Table 1. We found an improvement of clinical score (ie, DAS 28) in both groups at time 0 and time 1 , which was statistically significant $(\mathrm{p}=0.04$ and $\mathrm{p}=0.003$, respectively).

Neither differences nor improvements were found in both groups for disability score (ie, HAQ) at time 0 and time 1 , which was statistically nonsignificant $(\mathrm{p}=0.3$ and $\mathrm{p}=0.3$, respectively).

Levels of CRP were similar in both groups at time 0 and time 1 , which was statistically nonsignificant $(\mathrm{p}=0.8$ and $\mathrm{p}=0.1$, respectively).

Patients from group A being treated by ongoing inflixmab and common therapy (NSAIDs, steroids, and methotrexate), showed worsening IMT at time 1 compared to time 0 , which was statistically significant, while patients from group B showed light worsening of IMT at time 1 compared to time 0 and this value was not statistically significant. 
Table I Clinical, imaging and laboratory follow up of patient with RA

\begin{tabular}{|c|c|c|c|c|c|c|c|}
\hline & \multicolumn{3}{|l|}{ Group A } & \multicolumn{3}{|l|}{ Group B } & \multirow[b]{2}{*}{ Normal values } \\
\hline & Time 0 & Time I & $\mathbf{p}$ & Time 0 & Time I & $\mathbf{p}$ & \\
\hline IMT (mm) & $0.84 \pm 0.27$ & $1.17 \pm 0.39$ & $0.026, \mathrm{~s}$ & $1.07 \pm 0.25$ & $1.13 \pm 0.24$ & $0.2, \mathrm{~ns}$ & $<0.07$ \\
\hline DAS 28 & $7.0 \pm 1.4$ & $4.8 \pm 2.0$ & $0.04, \mathrm{~s}$ & $6.4 \pm 1.25$ & $4.9 \pm 1.96$ & $0.003, \mathrm{~ns}$ & \\
\hline HAQ & $1.78 \pm 0.75$ & $I .4 I \pm 0.67$ & $0.3, \mathrm{~ns}$ & $1.36 \pm 0.64$ & $\mathrm{I} . \mathrm{II} \pm 0.74$ & $0.3, \mathrm{~ns}$ & \\
\hline PCR (mgldL) & $2.54 \pm 1.99$ & $2.42 \pm 2.79$ & $0.8, \mathrm{~ns}$ & $2.16 \pm 2.10$ & $1.45 \pm 2.05$ & $0.1, \mathrm{~ns}$ & $0.0-1.0$ \\
\hline
\end{tabular}

Abbreviations: DAS, Disease Activity Score; HAQ, Health Assessment Questionnaire; IMT, intima-media thickness; ns, not significant; PCR, polymerase chain reaction; RA, rheumatoid arthritis.

\section{Discussion}

Patients affected by RA are more at risk of developing myocardial infarction and/or ischemic stroke when compared to the general population ${ }^{13,14}$ because the presence of chronic inflammation associated with the possible presence of further atherothrombotic risk factors such as hypertension, diabetes, smoking, dyslipidemia, and family history of atherothrombosis. In recent years several biological drugs have been associated with common treatment of chronic inflammatory disease such as RA, based on NSAIDs, steroids, and methotrexate. ${ }^{15}$ Prognosis, evaluated by disability and activity score, seems to be better for patients who have added biological drugs (ie, inflixmab, etanercept, adalimumab, anakinra, etc ${ }^{16}$ to traditional therapy.

Infliximab, an anti-TNF- $\alpha$ drug, is one of the most common biological drugs used for the treatment of RA. ${ }^{16}$ Treatment based on the administration of infliximab showed several improvements in the prognosis of RA, in particular advantages were found in several reports for disability index (eg, HAQ) and also for the disease activity score (eg, DAS 28). ${ }^{16}$ Improvements were discovered not only on the global assessment, on the evolution of pain, and on fatigue, but also for serological markers such as improvement of CRP levels and for the improvement of endothelial dysfunction. ${ }^{17-19}$ However, several side effects of treatment based on infliximab were reported. A higher risk $a$ priori of infection development ${ }^{20,21}$ has been underlined by several reports as the risk of recurrence of herpes zoster. ${ }^{22}$ Furthermore, from a cardiovascular point of view, several side effects have been reported for patients in ongoing treatment with infliximab such as congestive heart failure ${ }^{23,24}$ and an unassociated improvement of arterial stiffness. ${ }^{16}$

Data about the evolution of atherosclerosis for patients in ongoing treatment with infliximab are lacking in the literature. Our data showed an improvement of clinical parameters evaluated with the DAS 28 score for both groups with RA. On the other hand, no different values were discovered in both groups when we consider the disability index (ie, HAQ) and CRP levels at times 0 and 1. Further data regarding the clinical follow-up of chronic inflammatory disease are lacking in our study and this aspect may be considered as a partial study limitation.

However, the aim of our study is to focus on the evolution of the atherosclerosis in patients with RA treated or untreated with infliximab. Interestingly, patients with RA treated with infliximab showed worsening of asymptomatic atherosclerosis analyzed by IMT and increasing evidence of atherosclerotic plaques while the increase of IMT for patients with RA treated with traditional drugs (ie, without infliximab) was slight. We may speculate that the worsening of atherosclerosis in group A may be related to the possible influence of other traditional atherosclerotic risk factors that have not been considered in our report. However, although data on the influence of traditional atherosclerotic risk factors are lacking and actually should be considered as a study limitation, we should consider two further relevant aspects: first of all, we should relate this aspect to the altered metabolism of lipoprotein during treatment with infliximab that has been reported in the literature, ${ }^{25,26}$ but we may also consider that the natural history of RA, in particular its mortality, seems to be influenced mainly by atherothrombosis. ${ }^{27}$ Therefore, for this reason, patients treated with inflixmab may show a more advanced increase in IMT and asymptomatic plaques. We may speculate on the adverse cardiovascular outcome of such patients with RA treated with infliximab and this could also be in agreement with previous reports that reported an increased incidence of heart failure during treatment. It is not clear whether this aspect of treatment based on inflixmab may be a class effect or a dose-dependent effect or may be associated with an increased incidence of atherothrombosis of in any vascular region is not clear and should be evaluated by further prospective studies focusing on the incidences of thrombotic events. 


\section{Disclosure}

The authors report no conflicts of interest in this work.

\section{References}

1. Castelli WP. Epidemiology of coronary heart disease: the Framingham study. Am J Med. 1984;76(2A):4-12.

2. Novo S, Corrado E. Role of inflammation and infection in vascular disease. Acta Chir Belg. 2005;105:567-579.

3. Parke AL, Ioannides C, Lewis DFV, Parke DV. Molecular pathology of drugs-disease interaction in chronic autoimmune inflammatory diseases. Inflammopharmacology. 1991;1:3-36.

4. Parke AL, Parke DV, Avery Jones F. Diet and nutrition in rheumatoid arthritis and other chronic inflammatory diseases. J Clin Biochem Nutr. 1996;20:1-26.

5. Halliwell B, Gutteridge JMC. Free radicals in biology and medicine. New York, NY: Oxford University Press; 2000.

6. Jurcuț C, Jurcuț R, Tănăsescu C. Cardiovascular risk and rheumatoid arthritis: from mechanisms of atherosclerosis to therapeutic approach. Rom J Intern Med. 2004;42:659-669.

7. Van Doornum S, McColl G, Wicks IP. Accelerated atherosclerosis: an extraarticular feature of rheumatoid arthritis? Arthritis Rheum. 2002;46:862-873.

8. Ridker PM, Hennekens CH, Roitman-Johnson B, Stampfer MJ, Allen J. Plasma concentration of soluble intercellular adhesion molecule 1 and risks of future myocardial infarction in apparently healthy men. Lancet. 1998;351:88-92.

9. Ridker PM, Rifai N, Stampfer MJ, Hennekens CH. Plasma concentration of interleukin- 6 and the risk of future myocardial infarction in apparently healthy men. Circulation. 2000;101:1767-1772.

10. Bruunsgaard H, Skinhøj P, Pedersen AN, Schroll M, Pedersen BK. Ageing, tumour necrosis factor-alpha (TNF-alpha) and atherosclerosis Clin Exp Immunol. 2000;121:255-260.

11. Pascual-Ramos V, Contreras-Yáñez I, Villa AR, Cabiedes J, Rull-Gabayet M. Medication persistence over two years of follow-up in a cohort of early rheumatoid arthritis patients: associated factors and relationship with disease activity and with disability. Arthritis Res Ther. 2009;11:R26

12. Macedo A, Oakley S, Gullick N, Kirkham B. An examination of work instability, functional impairment, and disease activity in employed patients with rheumatoid arthritis. J Rheumatol. 2009;36:225-230.

13. Lévy L, Fautrel B, Barnetche T, Schaeverbeke T. Incidence and risk of fatal myocardial infarction and stroke events in rheumatoid arthritis patients. A systematic review of the literature. Clin Exp Rheumatol. 2008;26:673-679.
14. Aviña-Zubieta JA, Choi HK, Sadatsafavi M, Etminan M, Esdaile JM, Lacaille D. Risk of cardiovascular mortality in patients with rheumatoid arthritis: a meta-analysis of observational studies. Arthritis Rheum. 2008;59:1690-1697.

15. Zintzaras E, Dahabreh IJ, Giannouli S, Voulgarelis M, Moutsopoulos HM. Infliximab and methotrexate in the treatment of rheumatoid arthritis: a systematic review and meta-analysis of dosage regimens. Clin Ther. 2008;30:1939-1955.

16. Van Doornum S, McColl G, Wick IP. Tumor necrosis factor antagonists improve disease activity but not arterial stiffness in rheumatoid arthritits. Rheumatology. 2005;44:1428-1432.

17. Hürlimann D, Forster A, Noll G, et al. Anti-tumor necrosis factor-alpha treatment improves endothelial function in patients with rheumatoid arthritis. Circulation. 2002;106:2184-2187.

18. Sidiropoulos PI, Siakka P, Pagonidis K, et al. Sustained improvement of vascular endothelial function during anti-TNFalpha treatment in rheumatoid arthritis patients. Scand J Rheumatol. 2009;38:6-10.

19. Gonzalez-Juanatey C, Testa A, Garcia-Castelo A, Garcia-Porrua C, Llorca J, Gonzalez-Gay MA. Active but transient improvement of endothelial function in rheumatoid arthritis patients undergoing longterm treatment with anti-tumor necrosis factor alpha antibody. Arthritis Rheum. 2004;51:447-450.

20. Weisman MH. What are the risks of biologic therapy in rheumatoid arthritis? An update on safety. J Rheumatol Suppl. 2002;65:33-38.

21. Listing J, Strangfeld A, Kary S, et al. Infections in patients with rheumatoid arthritis treated with biologic agents. Arthritis Rheum. 2005;52:3403-3412.

22. Strangfeld A, Listing J, Herzer, et al. Risk of herpes zoster in patients with rheumatoid arthritis treated with ant-TNF-alpha agents. JAMA. 2009;301:737-744.

23. Curtis JR, Kramer JM, Martin C, et al. Heart failure among younger rheumatoid arthritis and Crohn's patients exposed to TNF-alpha antagonists. Rheumatology (Oxford). 2007;46:1688-1693.

24. Slørdal L, Spigset O. Heart failure induced by non-cardiac drugs. Drug Saf. 2006;29:567-586.

25. Saiki O, Takao R, Naruse Y, Kuhara M, Imai S, Uda H. Infliximab but not methotrexate induces extra-high levels of VLDL-triglyceride in patients with rheumatoid arthritis. J Rheumatol. 2007;34:1997-2004.

26. Popa C, van den Hoogen FH, Radstake TR, et al. Modulation of lipoprotein plasma concentrations during long-term anti-TNF therapy in patients with active rheumatoid arthritis. Ann Rheum Dis. 2007;66:1503-1507.

27. Levy L, Fautrel B, Barnetche T, Schaeverbeke T. Incidence and risk of fatal myocardial infarction and stroke events in rheumatoid arthritis patients. A systematic review of the literature. Clin Exp Rheumatol. 2008;26:673-679.
International Journal of General Medicine

\section{Publish your work in this journal}

The International Journal of General Medicine is an international, peer-reviewed open-access journal that focuses on general and internal medicine, pathogenesis, epidemiology, diagnosis, monitoring and treatment protocols. The journal is characterized by the rapid reporting of reviews, original research and clinical studies across all disease areas.

\section{Dovepress}

A key focus is the elucidation of disease processes and management protocols resulting in improved outcomes for the patient.The manuscript management system is completely online and includes a very quick and fair peer-review system. Visit http://www.dovepress.com/ testimonials.php to read real quotes from published authors. 